performed a series of experiments in $1898 .^{2}$ Since in the majority of our experiments the heart was more or less suddenly arrested, while respiration continued, the conclusions we came to were that when death immediately supervenes it is the result of the action of the electric current upon the heart, but whether this organ is paralysed by the current, killed by electrolytic changes, or brought to a standstill by great resistance offered through constriction of the peripheral arteries it is difficult to say.

MM. Prévost and Battelli ${ }^{3}$ of Geneva University found that alternating currents of comparatively feeble tension, 20-40 volts, produced fibrillary tremor of the heart; that the heart became paralysed, but that respiration continued; also that with alternating currents, $240-600$ volts, respiration and the beat of the heart were immediately arrested; also that high continuous currents were followed by similar effects, but that low voltages did not produce fibrillary tremor.

There are two main theories as to the cause of death in electric shock: (1) inhibition of the medulla oblongata, leading to arrest of respiration, followed by cessation of the beat of the heart; (2) death directly from the heart without the intermediary of respiration. Professor Bolam's and my own experiments rather showed death to be of cardiac origin.

After death from electric shock there is usually found rigidity of the muscles. The heart is flaccid, especially the right ventricle, which contains dark fluid blood. The left ventricle may be empty. The lungs may show nothing abnormal, or there may be signs of congestion if death was not immediate and artificial respiration had been resorted to. The pupils are dilated. The brain and spinal cord may be congested, and the abdominal veins and viscera full of dark blood. There may be hæmorrhage in the brain and petechial hæmorrhages in the pleura and pericardium. Although the blood is usually fluid, it is occasionally coagulated. On spectroscopic examination it is found to contain both oxyhæmoglobin and reduced hæmoglobin. I have already mentioned the chromolytic changes in the cerebral cells which Dr. Mott found in the portions of brain I submitted to him for microscopical examination.

A lecture on death from electrical shock would be incomplete were no reference made to the electrocution of criminals as carried out in the United States of America. Dr. Lésnce Minot has collected cases and summarixed them for us. It was in 1889 that the State of New York substituted for hanging death by electrocution. The use of alternating currents was adopted, the voltages varying from 1485 to 2000 and the contact from 10 to 52 seconds. On several occasions a second, third, and even a fourth contact had to be made before pulse and respiration ceased, and even then in one instance three minutes after successive contacts with 1790 volts, and 1900 for eight seconds, and although the current was gradually reduced to 250 volts for 53 seconds there were yet signs of life. Consciousness and respiration were usually abolished after the first contact, but the pulse remained perceptible even when the voltages were higher than 1400 . Necropsies of the criminals were made with care. No lesions of a gross character were found which could be regarded as characteristic of death by electricity. At the parts of the body where the electrodes had been applied there were signs of burning. On opening the bodies the blood was found to be dark and fluid, and the organs congested, especially the lungs ; there were subpleural and subpericardial ecchymoses ; in one instance there were capillary hæmorrhages in the floor of the fourth ventricle. None of these lesions are pathognomonic, since they are found in a certain number of deaths from violent causes, such as hanging, strangulation, and drowning.

Treatment of the injured.-For slight shock followed by recovery no treatment is required. For burns the application of boric acid compresses, or charcoal poultices if there is much destruction of tissue, is called for. Where an injured workman is in contact with, or cannot lose grip of, live metal the greatest care must be exercised in touching his body, for any attempt to separate the two might be followed by a disastrous shock to the person rendering assistance. Under any circumstances the breaking

2 Brit. Med. Jour., vol. i., 1898, p. 132.

3 Journal de Physiologie et de Pathologie Gènérales, Paris, 1889. 4 Des Accidents Causés par l'Jmploi Industriel de l'wiectricité
Paris, Steinheil, 1908. of the current means a fresh shock to the individual concerned. The rescuer should have his hands in indiarubber gloves or wrapped round with thick, dry rags. If it is a live wire with which contact has been made this should be cut if possible with long iron scissors in wooden handles. Once the circuit is broken, should there be no signs of life, the body must be placed upon its back and artificial respiration immediately resorted to and continued for a considerable time. Even if there is no quick response, artificial respiration should be continued. In our experiments we succeeded in resuscitating animals whose heart and respiration had ceased for several minutes, and at the Home Office Arbitration Inquiry concerning regulations for electric powerstations one of the witnesses stated that at his works in one man who had received 2000 volts shock the doctor pronounced life to be extinct, but his fellow workmen, to their credit, be it said, immediately resorted to artificial respiration, and as the result of having kept this up for over an hour the man is at work to-day.

Newcastle-on-Tyne.

\section{AN EXPERIMENTAL INVESTIGATION INTO THE QUESTION OF THE POSSIBILITY OF MODIFYING THE EFFECT OF AN INOCULATION OF TUBERCULIN BY COMBINING WITH IT A LOCAL AN ESTHETIC.}

\author{
BY H. WARREN CROWE, M.D. OXON.
}

MANY of the recently observed phenomena associated with the exploitation of that form of treatment known as " active immunisation " are extremely difficult of explanation on any hypothesis at present in vogue. It appears that the scope of modern theories of immunity is too contined. Anaphylaxis has produced many ingenious explanations, but none entirely satisfactory. The tuberculin "reaction" is another example and not less so, that curions effect which follows the repetition of equal small doses of tuberculin in phthisis, allied as it may or may not be to anaphylaxis or to the tuberculin reaction proper.

It will readil $\mathbf{v}$ be admitted that the nervous system plays the rôle of general supervisor to the various functions which together maintain that fine adjustment to environment which constitutes the fact of "life." In a former communication " I suggested that the nervous system might be endowed with a more particular control over certain of the processes of immunity. If such an influence could be demonstrated, then a new and hitherto unexplored field would be opened up for investigation, and, in fact, the present narrow scope of the theories of immunity would be enlarged.

Much patient endeavour must be expended before it could be claimed that such an elusive factor as "nerve control" was definitely proved to have any important bearing on the intimate processes of immunisation. Still, as a first halting step in that direction I venture to submit the investigations herein detailed. The only question upon which I attempt to throw light is whether the inoculation of tuberculin produces its effect in any degree by stimulating afferent nerve endings at the site of injection.

My procedure has been to combine a considerable proportion of a 4 per eent. solution of beta eucaine lactate with varying doses of tuberculin in various cases of phthisis under treatment by vaccines. Daily observations of the opsonic index were recorded during the whole course of the investigation, and as far as possible the blood specimens were taken at the same hour of the day. I must express my gratitude to Dr. Alexander Noble for the invaluable aid he has given me in his untiring efforts to make the indices reliable. It will readily be anderstood what an advantage there is in having the indices determined by an independent observer.

Table I. shows records of 24 inoculations of tuberculin given in the ordinary way, though seven of these were interspersed amongst doses combined with eucaine, with a view to providing controls.

Table II. consists of similar records where in each case the tuberculin was combined with from 0.3 to 0.5 c.c. of a 4 per cent. solution of eucaine in a $\frac{1}{4}$ per cent. lysol. 
TABLE I.--T.R., No Euoaine.

\begin{tabular}{|c|c|c|c|c|c|c|c|c|}
\hline No. & $\begin{array}{c}\text { Dose in } \\
\text { thousandths } \\
\text { of a mgr. }\end{array}$ & $\begin{array}{l}\text { Initials } \\
\text { of } \\
\text { patient. }\end{array}$ & Date. & $\begin{array}{l}\text { Opsonic } \\
\text { curve.* }\end{array}$ & $\begin{array}{c}\text { Tempera- } \\
\text { ture } \\
\text { curve. } \dagger\end{array}$ & Malaise. & $\begin{array}{c}\text { Auto- } \\
\text { inocula- } \\
\text { tions. }{ }^{+}\end{array}$ & Remarks. \\
\hline 1 & $1 / 100$ & M. B. & $12 / 7 / 09$ & $-F$ & Rise. & Yes. & No. & Prolonged negative phase. \\
\hline 2 & $1 / 50$ & c. G. & $30 / 7 / 09$ & F.R.F. & Rise. & Yes. & Yes, 1. & Prolonged negative phase. \\
\hline 3 & $1 / 100$ & " & $27 / 10 / 09$ & F.R.F. & Rise. & Yes. & Yes, 2. & Slighter phases. \\
\hline 4 & $1 / 100$ & $"$ & $10 / 11 / 09$ & F.R.F. & Rise. & Yes. & Yes, 2. & Big reaetion on fifth day. \\
\hline $\begin{array}{l}5 \\
6\end{array}$ & $\begin{array}{l}1 / 100 \\
1 / 100\end{array}$ & $\begin{array}{c}\text { W. G. } \\
, "\end{array}$ & $\begin{array}{r}25 / 11 / 09 \\
1 / 12 / 09\end{array}$ & $\begin{array}{l}\text { R.F. } \\
\text { Rise. }\end{array}$ & $\begin{array}{l}\text { Rise. } \\
\text { High. }\end{array}$ & $\begin{array}{l}? \\
?\end{array}$ & $\begin{array}{c}\text { Yes, } 1 . \\
?\end{array}$ & $\begin{array}{l}\text { Acute case, difficult to adjudge as auto- } \\
\text { inoculations continuous. }\end{array}$ \\
\hline 7 & $1 / 25$ & J.C. & $2 / 9 / 10$ & R.F.R. & Rise. & Yes. & Yes, 2. & This patient had a very subnormal tempera- \\
\hline 8 & $1 / 25$ & ", & $9 / 9 / 10$ & R.F.R. & Fall. & No. & ? (1). & $\begin{array}{l}\text { ture; this fluctuated, but did not rise above } \\
\text { normal. What symptoms of negative phases }\end{array}$ \\
\hline 9 & $1 / 10$ & " & $16 / 9 / 10$ & R.F.R. & R.F. & No. & Yes, 1. & occurred were slight. \\
\hline 10 & $1 / 10$ & $"$ & $24 / 9 / 10$ & R.F.R. & Nil. & No. & Yes, 2 & \\
\hline 11 & $1 / 100$ & M. B. & $31 / 3 / 10$ & F.F. & Rise. & Yes. & No. & Prolonged negative phase. \\
\hline 12 & $1 / 100$ & " & $7 / 4 / 10$ & F.F. & Rise. & Yes. & Yes, 1. & Cf. No. 1 above. Still longer negative phase. \\
\hline 13 & $1 / 25$ & , & $7 / 6,10$ & R.F.R. & Nil. & No. & No. & Typical tuberculin curve in phthisis as Fig. (A). \\
\hline 14 & $1 / 15$ & , & $21 / 6 / 10$ & R F.R. & Rise. & Yes. & Yes, 1. & Also this one; cf. Table II., Nos. 4 and 5. \\
\hline 15 & $1 / 5$ & , & $18 / 9 / 10$ & RR.F.R. & Rise. & Yes. & Yes, 1. & Follows after Table II., No. 8, which cf. \\
\hline 16 & 1,25 & E. $R$. & $14 / 9 / 10$ & R.F. & Nil. & No. & Yes, 1 . & This case always had a high temperature, \\
\hline 17 & $1 / 10$ & , & $20 / 9 ; 10$ & R.F.R. & Nil. & Yes. & Yes. 2. & though well and walking; ? nervous. \\
\hline 18 & 1,50 & M. P. & $30 / 7 / 09$ & F.R.FR. & Rise. & Yes. & No. & Not typical curves for large prolonged nega- \\
\hline 19 & $1 / 50$ & " & $11 / 8 / 09$ & F.F.R. & Rise. & Yes. & No. & $\begin{array}{l}\text { tive and positive phases, were accompanied } \\
\text { by marked symptoms. The lesion: old single }\end{array}$ \\
\hline 20 & 150 & ., & $25,8,09$ & FFE.R. & Rise. & Yes. & No. & focus, suddenly aflame. \\
\hline 21 & $1 / 100$ & R. P. & $16,8 / 10$ & R.F.R. & Rise. & No. & Yes, 1. & Complicated by acute tubercular hip with auto- \\
\hline 22 & 1,50 & , & $26,8 / 10$ & F.F.R. & F.R. & No. & Yes, 2 . & $\begin{array}{l}\text { inoculations going on from that, but not } \\
\text { affecting the index as done with human germs }\end{array}$ \\
\hline 23 & $1 / 50$ & ,. & $2 / 9 / 10$ & R.F.RF. & Rise. & No & Yes, 2. & $\begin{array}{l}\text { affecting the index as done with human germs } \\
\text { as same curves occurred after joint and tem- }\end{array}$ \\
\hline 24 & 1,10 & ," & $23 / 9 / 10$ & R.F.RE. & F.R.F. & No: & Yes, 2. & perature subsided. Cf. Table İ., No. 10. \\
\hline
\end{tabular}

* In this column the tirst letter indicates whether the index has risen or fallen on the following day. The other letters indicate the subsequent course of the opsonic curve. Thus, for example, No. 18, F.R.FR., shows that the curve beging with a fall. then follows a rise, and a subsequent fall and rise thus : $\vee \vee . \quad A-$ means no change in the index. If the reader is sufficiently interested in the subject he would find that by drawing diagrammatic representations of the letters under this column he would more easily compare the two tables.

This column, similarly to the preceding one, indicates the general course of the temperature.

This column takes note of secondary curves, due probably to considerable auto-inoculations, appearing in the course of the primary curve. which result from the tuberculin inoeulation.

TABLE II.-T.R. + Encaine.

\begin{tabular}{|c|c|c|c|c|c|c|c|c|}
\hline No. & $\begin{array}{l}\text { Dose in } \\
\text { thousandths } \\
\text { of a mgr. }\end{array}$ & $\begin{array}{c}\text { Initials } \\
\text { of } \\
\text { patient. }\end{array}$ & Date. & $\begin{array}{l}\text { Opsonic } \\
\text { curve.* }\end{array}$ & $\begin{array}{c}\text { Tempera- } \\
\text { ture } \\
\text { curve. }\end{array}$ & Malaise. & $\begin{array}{l}\text { Auto- } \\
\text { inocula- } \\
\text { tions. }\end{array}$ & Remarks. \\
\hline 1 & 110 & J. C. & $1 / 10,10$ & Nil. & $\mathrm{Nil}$ & No. & No. & Follows Table I., No. 10, which ef. \\
\hline 2 & $1 / 50$ & M. B. & $10 / 5 / 10$ & Nil. & Fall. & No. & No. & Practically no effect. \\
\hline 3 & $1 / 50$ & , & $17 / 510$ & Nill. & R.F. & No. & No. & Temperature from $98^{\circ}$ to $98^{\circ} 6^{\circ} \mathrm{F}$ \\
\hline 4 & $1 / 25$ & ," & $24,5,10$ & F.RR.F. & Fall. & No. & No. & These show perfect curves such as rarely, if \\
\hline 5 & $1 / 25$ & ", & $31 / 5 / 10$ & F.R.F. & Nil. & No. & No. & $\begin{array}{l}\text { ever, seen in phisisis. Followed oy 1avie 1., } \\
\text { No. } 13 .\end{array}$ \\
\hline 6 & $1 / 15$ & , & $14,6^{\prime} 10$ & Rise. & Fall. & No. & No. & Very short negative curve probable. \\
\hline 7 & $1 / 10$ & , & $30 / 8 / 10$ & Nil. & Nil. & No. & No. & Third repetition of dose. \\
\hline 8 & $1 / 5$ & , , & $11 / 9 / 10$ & Rise. & Fall. & No. & No. & Short negative curve proved. \\
\hline 9 & $1 / 25$ & R. P. & $9 / 9 / 10$ & R.F.R. & R.F. & No. & Yes. 1. & Cf. Table I., Nos. 21, 22, 23, and 24. \\
\hline 10 & $1 / 10$ & , & $16 / 9 / 10$ & F.R.FR. & Fall. & No. & Yes, 1. & Cf. particularly Table I., No. 24. \\
\hline 11 & $1 / 10$ &, & $30 / 9 / 10$ & R.R.F. & Fall. & No. & No. & Similar to No. 8 above. \\
\hline 12 & $1 / 5$ & , & $7 / 10 / 10$ & F.R. & Fall. & No & No. & No subjective effect in any of this series \\
\hline 13 & $1 / 5$ & , , & $14 / 10 / 10$ & F. - R. & RR.F. & No. & $? 1$. & $\begin{array}{l}\text { (Nos. } 9 \text { to } 15 \text { ), except the last, though large } \\
\text { doses for a tebrile patient. }\end{array}$ \\
\hline 14 & $1 / 25$ & ," & $21 / 10 / 10$ & R.RR. & F.FF. & No. & No. & \\
\hline 15 & $1 / 25$ & , & $28 / 10 / 10$ & - R.F. & RR.F. & Yes. & Yes, 1. & \\
\hline 16 & $1 / 25$ & E. $\mathbf{B}$. & $11 / 6 / 10$ & F.RR.F. & R.FF. & No. & No. & Much lung involved in this case: febrile, \\
\hline 17 & $1 / 20$ &, & $18 / 6 / 10$ & F.F.RF. & FF.RF. & No. & Yes, 1. & $\begin{array}{l}\text { sputum } 4 \text { onnces, temperature } 99^{\circ} \text { to } 100^{\circ} \\
\text { noctu. History six years. }\end{array}$ \\
\hline 18 & $1 / 20$ & , & $25 / 6 / 10$ & R.F.R. & Nil. & No. & No. & \\
\hline 19 & $1 / 5$ & , & $14 / 10 / 10$ & F.RR.F. & $N i l, \mathbf{R}$ & No. & No. & \\
\hline 20 & 15 & , & $23 / 10 / 10$ & F.RR. & Nil. & No. & No. & \\
\hline 21 & $1 / 5$ & , & $30 / 10: 10$ & R.FF.R. & F.RR. & Yes. & Yes, 1. & This dose exceptional effect, as if no eucaine. $\$$ \\
\hline 22 & 115 & Q. H. & $15 / 6 / 10$ & Rise. & Fall. & No. & No. & Short negative curve proved as in II., $8 \mathrm{cf}$. \\
\hline 23 & 110 & , & $5 / 7 / 10$ & - RR. & Fall. & No. & No. & Probably as previons. \\
\hline 24 & $1 / 10$ & F. B. & $11 / 11 / 10$ & Nil. & Nill. & No. & No. & This is same case as above, $16-21$. \\
\hline
\end{tabular}

* it See footnotes under Table I.

I I gave tbe eucaine alone first, then without withdrawing the needle gave the tuberculin. The result was comparable to several of the doses under Table I. 
Of the patients referred to in the second table, 2 exhibited temperature charts steadily above normal, 2 showed normal temperatures in the morning, and 1 showed a subnormal temperature throughout. The marginal notes give an indication of the symptoms and conditions which called for comment and also draw attention by cross references to corresponding doses and other comparisons in the two tables.

Before examining the essential points of difference in the two tables it would simplify the business of comparison to describe what seem to be the main characteristics of the opsonic curve as it is seen after an inoculation of tuberculin in phthisis, and to show how it differs from that following tuberculin in a chronic lesion in some other locality. In the paper above referred to an attempt was made to show that the tuberculo-opsonic curve in phthisis was a complex curve which could generally be resolved without difficulty into two or more successive curves, overlapping each other in their incidence; and there it was further suggested that these curves consisted of a primary curve due to the inoculation and one or more secondary curves due to auto-inoculations set up as a result of hyperæmia in the diseased area in the lung. The accompanying figure shows such a curve (A), and for

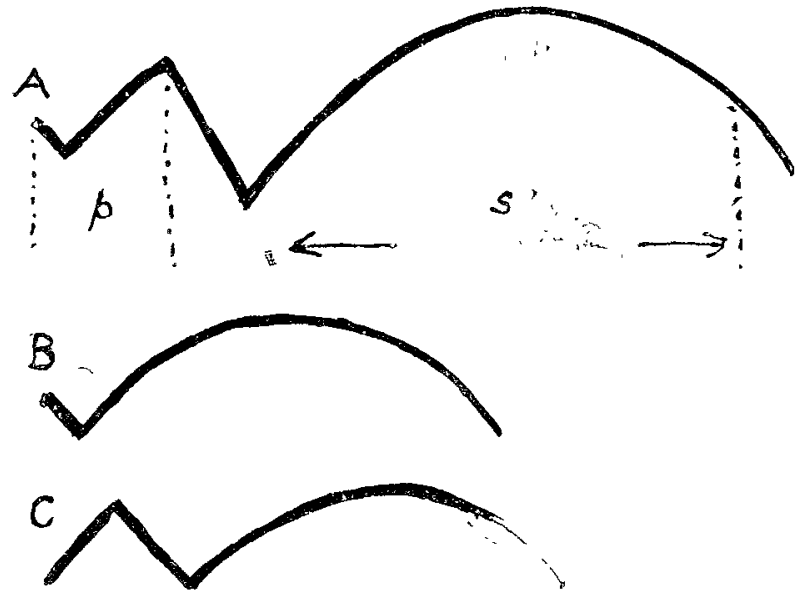

Primary and secondary inoculation curves : $p$, primary ; $s$, secondary.

comparison is shown what may be termed an ideal inoculation curve (B). A third curve (C) is found to occur not infrequently in febrile phthisis. It consists of an appreciable rise lasting for 24 hours or longer, followed by a fall lasting about the same length of time and succeeded by a prolonged positive phase. Wright has described such a preliminary rise as occurring after an inoculation in other conditions, but I understand that he has found it to be of very short duration, being rapidly succeeded by the negative phase. Now this prolonged preliminary rise occurs no less than ten times quite unmistakeably in Table $\mathrm{I}$. (Nos. $5,8,9,10,13,14$, $16,21,23$, and 24 , and perhaps 7 and 17), whereas in Table II. it occurs only twice (Nos. 9 and 21). Of the two last mentioned the first was undergoing at the time large auto-inoculations with high temperatures, which probably vitiated the curve, and the other has been shown to be possibly uninfluenced by the eucaine.

Look again at the figure (A). Such a curve is found in 16 out of the whole list, when no encaine was added to the dose, and in 5 of the remainder was obscured or replaced by a quite uncomfortably prolonged negative phase, accompanied by malaise. In Table II. the curve is only found 5 times altogether, and then wi h diminished distinctness. Compare Table II., No. 10, on Sept 16th, where eucaine was used, with Table I., No. 24, on the 23rd of the same month, where the same dos a was given only a week later, but without eucaine. Compare also Table II., Nos. 4 and 5 , with Table I., No. 13. Finally, malaise follows 13 of the doses without eu saine and only 2 in Table II., of which one is again the doubtful No. 21 .

Conclusions. - 1 . There is a distinct difference in the response to an inoculation of tuberculin in phthisis if eucaine be conbined with the dose. 2. The chief proof of this rests on the form of opsonic curve which follows such doses as compared with doses in which no encaine was given. 3. There is a possibility that an inoculation of tuberculin produces its effect in part by stimulating the central nervous system. 4. Such stimulation may take place at the site of inoculation. Yelverton, Devon.

\section{SOME REMARKS ON PANTOPON AN ESTHESIA.}

BY C. LOUIS LEIPOLDT, F.R.C.S. ENG., AN IESTHETIST TO 'PHE GERMAN HOSPITAL, DALSTON ; CLINICAL ASSISTANT, VICTORIA HOSPITAL FOR CHILDREN, CHELSEA.

DURING the last ten years so many new methods of inducing and maintaining surgical anæsthesia bave been placed before the profession that it seems almost supererogatory to add yet another to the number demanding investigation and criticism. But it is fairly obvious that none of the methods now in use can honestly be styled ideal; the very fact that so many novelties are competing for popularity is a proof of the absence of a thoroughly satisfactory anæsthetic. So far as I am aware, up to the present no report of any case in which pantopon has been used as a " combined anæsthetic" has been published in English medical literature, and the conclusions of continental surgeons with regard to this new adjuvant have hitherto received scant attention in this country. As I have now for some time been using the drug a preliminary résumé of the results obtained with it may not be without interest to those who are not already acquainted with its possibilities, and it is with that object that these initial notes have been written.

In the early part of $1909 \mathrm{Sahli}^{1}$ of Berne, experimenting with the various alkaloids contained in crude opium, concluded that the most effective narcotic was a definite, stable solution of these alkaloids, in which the relative strength of the various constituents was definitely known or could be accurately measured. At his request, Schärger of the firm of La Roche prepared such a mixture. which was provisionally styled "pantopon" (from $\pi \alpha \nu$ all and "ot $\pi$ os juice). This, briefly, is a mixture of the soluble chlorides of opium in which the relative strengths of the following are claimed to be known: morphine, narcotine, codeine, papaverine, narceine, thebeine, hydrocotarnine, codamine, laudanine, laudaniảine, laudanoeine, meconidine, papaveramine, protopine, lanthopine, cryptopine, goscopine, oxynarcodine, xanthaline, and tritopine. It is obtained as an amorphous, yellowish-brown powder, resembling somewhat finely powdered crude opium, easily soluble in water, less easily in alcohol and acetone, and forming a clear, colourless, or slightly brownish solution which is apparently quite stable at the ordinary temperatures, and which is faintly acid in reaction. One gramme of pantopon is estimated as being equivalent to five grammes of 10 per cent. morphine and 18 per cent. opium, but this estimate is probably too low, especially for anæsthetic purposes. The powder and the solutions have been extensively tried in continental clinics as narcotics and anodynes, and are claimed to be superior to other opium compounds and derivatives. Already a large number of reports on the clinical usefulness of the combination have been published, among which the work of Hallervorden, ${ }^{2}$ Heimann, ${ }^{3}$ Rodari, ${ }^{+}$Gottlieb, ${ }^{5}$ Witowski, ${ }^{6}$ and Raffalovitch ${ }^{\top}$ contains much interesting information. For some time the drug has been used as an adjuvant to general anresthesia, and the results so far obtained, notably by Brustlein, ${ }^{\circ}$ are so eminently satisfactory that the combination deserves wider trial and investigation. It is almost regularly employed at the German Hospital, Dalston, and has proved remarkably useful.

Combined anæsthesia, in which narcotics are used as a preliminary to the administration of the general anæsthetic, has now been so generally tested that we are in a position to draw certain definite conclusions with regard to its advan. tages and limitations. The combinations are so varied, ranging from the chloral-urethane group to that in which morphia in some form, either alone or combined with hyoscine, is administered, that it is not easy to collate the findings of various observers. The whole question opens up

1 Sahli: Minchener Medizinische Wochenschrift, No. 26, 1909. Therapeutische Monatshefte, No. 1, 1909.

2 Hallervorden: Uber die Anwendung des Pantopons, Therapie der Gegenwart, 1910, No. 5.

Heimann: Munchener Medizinische Wochenschrift, No. 7, 1910.

4 Rodari: Therapeutische Monatshefte, 1909.

5 Gottlieb und v.d. Eeckhart: Festschritt fur Schmiedeberg, p. 235.

6 Witowski: Archiv fur Experimentelle Pathologie und Pharma-

kologie, Band xvii. V. Schroeder: Ibid., Band vii.

7 Raffalovitch: Deutsche Medizinische Wochenschrift, 1910. 